\title{
Research on the Transformation and Upgrading of Equipment Manufacturing in Northeast China
}

\author{
Dan Bai ${ }^{1, a}$ and Yang Tang ${ }^{2, b^{*}}$ \\ ${ }^{1}$ School of Management, Dalian University, Dalian, China, 116622 \\ ${ }^{2}$ School of Management, Dalian University, Dalian, China, 116622 \\ abaidan@dlu.edu.cn, btangyangup@163.com
}

\begin{abstract}
Keywords: North-east area;Equipment manufacturing;Transformation and Upgrade
\end{abstract}
\begin{abstract}
Northeast China is the cradle of China's industry and is one of the three major bases for the equipment manufacturing industry in our country. This article points out the major problems that the equipment manufacturing industry in Northeast China faces through consulting literature and field visits The problems such as unreasonable industrial structure, the lack of capacity of independent innovation, the low degree of externalization of professional division of labor, the short industrial chain, low intelligence and information technology. At the same time, this paper puts forward that emancipating the mind, accelerating the reform of the system and mechanism, implementing the innovation-driven strategy, and improving the intermediary service and information construction are the necessary ways to revitalize the Northeast equipment industry.
\end{abstract}

\section{Introduction}

Northeast China is an old industrial base with the title of "Republic Ministry of Equipment." After nearly 70 years of development, a large number of equipment manufacturing enterprises have emerged such as Harbin Electric, Hafei, FAW, Dalian Machine Tool, Dalian Shipbuilding Heavy Industry, Shenyang Aircraft and so on. But we also want to see the hidden crisis behind the fruitful results. The current heavy industrial economy continued downward, lack of market demand to the industry dilemma. Northeastern equipment manufacturing industry faces the problems of weak market competitiveness, weak independent R \& D capability, limited core technologies, low total contracting capacity, low degree of externalization of professional division of work, short industrial chain, low level of informationization and lack of intermediary services. Therefore, with the new round of "revitalization of northeast China" and the "Belt and Road" strategy, northeast China's equipment manufacturing industry has enjoyed major favorable policies. Clear their own advantages and shortcomings, focus on overcoming shortcomings, to the high-end, intelligent transformation and upgrading, for the northeast equipment manufacturing industry reform is of great significance.

\section{The Northeast Equipment Manufacturing Industry Profile}

Northeast China equipment manufacturing industry output data. In the first year of the thirteenth five-year plan, the added value of the equipment manufacturing industry in Liaoning Province accounted for $34.1 \%$ of the industrial enterprises in the scale, an increase of 1.8 percentage points over the previous year and realized a profit of 31.92 billion yuan, accounting for $47.6 \%$ of the province's industry. In 1985, there were 859 equipment manufacturing enterprises above designated size in Jilin Province, achieving a total industrial output value of 264.3 billion yuan, an increase of $7.2 \%$ over the same period of last year, an increase of 1.6 percentage points higher than that of the province's industry. In the whole year, the total added value of all industrial enterprises in Heilongjiang Province was 368.61 billion yuan, up by $2.1 \%$ over the previous year at a comparable price, with added value accounting for $24.0 \%$ of the GDP.

Northeast equipment manufacturing industry status. In the early days after the founding of New China, the state established a large number of equipment manufacturing enterprises in the northeast 
region, and the northeast region became the most important production base of machinery and equipment in the country. The added value of the equipment manufacturing industry accounted for more than 20\%. After the reform and opening up, the Yangtze River Delta and the Pearl River Delta made remarkable achievements because of the prosperous development of the equipment manufacturing industry due to the advantages of system and capital. At present, the three major manufacturing bases for manufacturing equipment in the Yangtze River Delta, Pearl River Delta and Northeast China have been formed. As a result, the share of the equipment manufacturing industry in the Northeast China has been greatly reduced. Now it occupies the last place in the three major equipment manufacturing bases.

Northeast equipment manufacturing industry status quo. Northeast China's equipment manufacturing industry is a product of the planned economy. Gradually began to lose ground in the tide of market economy. After realizing its own weaknesses and crises, the equipment manufacturing industry in Northeast China began to gradually change its thinking on development. After several rounds of rejuvenation policies by the central government, the condition of the equipment manufacturing industry has been somewhat improved. The status of pillar industries has become clearer. The growth rate of industrial output has begun to gradually increase. The construction of industrial agglomeration areas has been continuously promoted, and the effectiveness of technological innovation is also increasingly prominent. However, there are still some basic problems that need to be solved urgently.

\section{Existing Problems}

Unreasonable industrial structure. There are two major problems with the equipment manufacturing industry in Northeast China. First, at the beginning of the founding of the China, a large number of state industrial enterprises have been established in the northeast region, and industrial enterprises have long dominated the economy in northeast China. State-owned equipment manufacturing enterprises dominated the industries in the northeast for a long time. Although in recent years the state has taken such measures as enterprise restructuring, optimization and reorganization, due to the double obstacles of the system and mechanism, the adjustment of the industry is slow and the market competitiveness is declining. As equipment manufacturing enterprises to invest large, high threshold, new technology development cycle length, leading to private enterprises, joint ventures difficult to enter. Second, the traditional equipment manufacturing industry accounts for a large proportion. The proportion of emerging computers, telecommunications and other electronic equipment manufacturing industries is too low, which is in striking contrast with the Pearl River Delta and the Yangtze River Delta. The irrational industrial structure has become a evident issue in the equipment manufacturing industry.

$R \& D$ investment accounted for a low, lack of capacity for independent innovation. After years of development, enterprises in Northeast China have gradually realized the importance of technological innovation and continuously improved the capability of independent innovation and market competitiveness. However, the R \& D investment is seriously insufficient, which is far lower than that of developed countries. As a result, the enthusiasm of $\mathrm{R} \& \mathrm{D}$ personnel is not high, the output rate of results is naturally not high, and the enterprises have no staying power. The innovation ability of key technologies is also low. The core technologies and key technologies are still lagging behind international standards. A large number of equipment and technologies should be imported from abroad without any bargaining power. Few original technologies and products, lack of originality, breakthrough innovation and other issues is also very obvious.

Lower degree of externalization of professional division of labor, short industrial chain. Northeast China has a large number of equipment manufacturing enterprises, which seem to form a good industrial agglomeration, but convergence of industries, similar enterprises and products have vicious competition. Lack of awareness of social division of labor cooperation, professional division of labor is not strong coordination ability. No matter the size of an enterprise, there are still a large number of phenomena in which departments set up a comprehensive system. The key components and production services are still only completed by the internal organization, equipment manufacturing enterprises did not make full use of external companies to reduce costs, but also not conducive to 
enterprises to further expand and strengthen, leading to the entire Northeast equipment manufacturing industry chain is short.

Lower overall project contracting capacity. System design, system integration, project general contracting, and all the supporting service capacity is measure a good standard of the equipment manufacturing industry enterprise strength. International multinational corporations have accumulated a great deal of experience in this regard, and their overall strength is strong. Equipment manufacturing enterprises in Northeast China only focus on stand-alone production, but do not grasp the whole package, full service, leading to China's large-scale project contractors are mostly foreign companies, and most of the value-added industries are also owned by foreign enterprises.

Low intelligence and information technology. Equipment manufacturing intelligence, information technology is mainly used in the production and management of enterprise information technology to enable enterprises to shorten the production process, improve management efficiency. The lack of information sharing has led to the separate development of equipment manufacturing enterprises in Northeast China, which can not effectively grasp the market demand, resulting in an imbalance between supply and demand and waste of resources. In the southeast coastal areas, for example, the production process has been greatly reduced by mechanical intelligence and the number of workers in need has also been greatly reduced, and even many unmanned factories have emerged. However, due to institutional reasons in the northeast region, the enterprises have not yet carried out a new round of production technologies and replaced them on a large scale.

Inadequate intermediary service. Intermediary services include financial institutions, investment and financing, legal services, financial services, management consulting, technical services, assessment and certification. The lack of intermediary services has led to difficulties in the transformation and promotion of enterprise achievements. The funds of enterprises can also be difficult to turn around. The demand for organizational structure design, brand value enhancement and long-term development plan preparation is also difficult to meet.

\section{Countermeasures and Suggestions}

Change thinking, optimize the industrial structure. Improve government service attitude, further promote the simplification of power and improve efficiency. The government should attach importance to commerce, optimize the business environment, build a new type of relationship between government and enterprises and eliminate the "acquaintance economy" so that enterprises can make money and the local economy has been developed. Further rationalize the relationship between the government and the market and grasp the relationship between the government's tangible hand and the invisible hand of the market. Deepen the reform of state-owned enterprises, enhance the voice and control of state-owned enterprises in key industries. Promote the development of non-public ownership economy, strengthen a group of private-owned enterprises and encourage social capital to participate in more major social projects.

Increase the proportion of $R \& D$ investment, focus on resources to capture the core technology. Innovation is the endogenous impetus to the long-term development of the enterprise. The equipment manufacturing industry is an industry that needs to invest in research and development for a long time. Enterprises should gradually optimize the talent structure, increase investment in science and technology, and optimize the investment structure of science and technology. The government should build a platform for learning and exchange, strengthen the awareness of innovation among enterprises, introduce relevant incentive measures to improve incentives for innovative enterprises and innovative personnel. The government has perfected the cooperation mechanism of production, study and research, and they are mutually beneficial and common development.

Build a platform for development, coordinate regional development and extend the industrial chain. Industrial homogeneity and short industrial chain two major problems can be solved using regional integration. From the perspective of synergistic development of the regional industries, Northeast should abandon its own mindset of development according to the administrative divisions and make overall planning and rational layout for the development. The development priorities of all 
provinces should be clarified and a modern industrial system with regional characteristics should be established. At the same time, large enterprises should find their own core strengths, concentrate their resources to make them bigger and stronger, firmly occupy the leading position, and subcontract the appropriate businesses to the upstream and downstream companies, so as to lighten the overall development burden of enterprises and promote the coordinated development of the region, Extend the industrial chain.

Improve the level of complete sets and project contracting capacity. China's equipment manufacturing has gradually shifted from labor-intensive to technology-intensive. While upgrading large-scale production technologies, large-scale enterprises should step up their supply chain construction and upgrade their overall design, system integration and complete sets of standards. Domestic enterprises should actively exchange ideas with multinational enterprises, introduce - absorb innovate, upgrade their professional standards, bid jointly with advanced enterprises, obtain general contracting opportunities, and grasp the specific operational procedures of general contracting in practice.

Speed up the equipment manufacturing industry informative and intelligent process. Local governments introduced preferential policies to support equipment manufacturing enterprises to intelligent and informative transformation, improve the production level and production efficiency, reduce the use of manpower, material and financial resources, and effectively improve the profitability of enterprises. They should also seize the opportunity to establish a unified information sharing service platform to share industry information, grasp the market demand, reduce the vicious competition, but also can effectively reduce duplication of construction and waste of resources.

Improve the intermediary service system. Relying on industry, integrate the advantages of resources, develop the network system of regional productivity promotion centers, and establish and improve the intermediary service system. The establishment of intermediary service organization system in northeast China, such as trade associations and chambers of commerce, and strengthening the introduction of international-level management consulting agencies, legal consulting agencies and financial management agencies help enterprises to achieve further development. A number of business incubators and Productivity Promotion Center and other intermediary service organizations can effectively promote the growth of small and medium-sized enterprises and the transformation of scientific and technological achievements so as to help revitalize the economy in the Northeast as soon as possible.

\section{Acknowledgements}

This work is partially supported by National Social Science Foundation of China No. 16BGL021. The authors also gratefully acknowledge the helpful comments and suggestions of the reviewers, which have improved the presentation.

\section{References}

[1] C.F. Yang and Y. Liu:Research on Transformation and Upgrading of Equipment Manufacturing Industry in Northeast Old Industrial Base [J]. Business \& Trade Practice, 2017, (18): 27-28.(In Chinese)

[2] J. Zhang: Literature Review of Equipment Manufacturing Industry [J]. Modern Business, 2014, (35): 42-43.(In Chinese)

[3] M. Zhang:Northeast China manufacturing industry independent innovation motivation factor analysis [J]. Journal of liaoning university (philosophy and social sciences edition), 2013, 9 (4) : 48-53.

[4] F.F. Jiang and X.M. Sun:Research on the Characteristic Service Trade of Northeast Old Industrial Base [J] .Journal of Economic Research, 2012, (35): 37-38.[5](In Chinese) 
[5] T. Sun, S.K. Zhao and Z. Qiao:Research on the Development and Countermeasures of Equipment Manufacturing Industry in Transition and Upgrading in China [J]. Industrial and Technological Economy, 2011,30 (05): 38-41.(In Chinese)

[6] T. Sun and S.L. Gong:Northeast China equipment manufacturing industry innovation status quo and countermeasures [J]. Economic Zoning, 2011, (05): 59-61 + 101.(In Chinese)

[7] Editorial Department Editorial Review of Liaoning Province in 2009 Economic Operation [J]. Liaoning Economy, 2010, (02): 34-35.(In Chinese)

[8] X. Wang:China's equipment manufacturing total factor productivity measurement [D]. Southwest University of Finance and Economics, 2010.(In Chinese)

[9] F.J. Wang:Evolution of comparative advantage and upgrading of equipment manufacturing industry - based on the empirical study of Liaoning Province [D]. Northeast Normal University, 2009(In Chinese)

[10] Y.N. Liu:Northeast old industrial base equipment manufacturing cluster competitiveness [D]. Harbin Institute of Technology, 2008.(In Chinese)

[11]L. Zhao:Analysis and Countermeasures of Equipment Manufacturing in the Three Provinces of Northeast [J]. Business Economy, 2008, (11): 17-18.(In Chinese)

[12]Z.Z. Wu, D.T. Wu and X.J. Feng:Study on the Status and Changes of Equipment Manufacturing Industry in Northeast China [J]. Human Geography, 2007, (01): 86-91.(In Chinese) 